\title{
Analysis of plot-level volume increment models developed from machine learning methods applied to an uneven-aged mixed forest
}

\author{
Seyedeh Kosar Hamidi ${ }^{1}$ Eric K. Zenner ${ }^{2} \cdot$ Mahmoud Bayat $^{3}$ [D $\cdot$ Asghar Fallah $^{1}$
}

Received: 10 March 2020 / Accepted: 13 October 2020 / Published online: 12 January 2021

○ INRAE and Springer-Verlag France SAS, part of Springer Nature 2021

\begin{abstract}
Key message We modeled 10-year netstand volume growth with four machine learning (ML) methods, i.e., artificialneural networks (ANN), support vector machines (SVM), random forests (RF), andnearest neighbor analysis (NN), and with linear regression analysis.Incorporating interactions of multiple variables, the ML methods ANN and SVMpredicted nonlinear system behavior and unraveled complex relations withgreater accuracy than regression analysis. Context Investigating the quantitative and qualitative characteristics of short-term forest dynamics is essential for testing whether the desired goals in forest-ecosystem conservation and restoration are achieved. Inventory data from the Jojadeh section of the Farim Forest located in the uneven-aged, mixed Hyrcanian Forest were used to model and predict 10-year net annual stand volume increment with new machine learning technologies.

Aims The main objective of this study was to predict net annual stand volume increment as the preeminent factor of forest growth and yield models.

Methods In the current study, volume increment was modeled from two consecutive inventories in 2003 and 2013 using four machine learning techniques that used physiographic data of the forest as input for model development: (i) artificial neural networks (ANN), (ii) support vector machines (SVM), (iii) random forests (RF), and (iv) nearest neighbor analysis (NN). Results from the various machine learning technologies were compared against results produced with regression analysis. Results ANNs and SVMs with a linear kernel function that incorporated field-measurements of terrain slope and aspect as input variables were able to predict plot-level volume increment with a greater accuracy (94\%) than regression analysis (87\%). Conclusion These results provide compelling evidence for the added utility of machine learning technologies for modeling plot-level volume increment in the context of forest dynamics and management.
\end{abstract}

Keywords Machine learning methods $\cdot$ Modeling $\cdot$ Model comparison $\cdot$ Plot-level volume estimates

Handling editor: John M Lhotka

The concept of the paper was conceived by SKH. Field data were evenly collected by SKH and AF (2003 and 2013 data). All authors had various roles in (i) analyzing and formatting the data and (ii) preparing and editing the revised manuscript.

Mahmoud Bayat

Mbayat@rifr-ac.ir

1 Sari Agriculture Sciences and Natural Resource University, Sari, Mazandaran, Iran

2 Department of Ecosystem Science and Management, The Pennsylvania State University, Forest Resources Building, University Park, State College, PA 16802, USA

3 Research Institute of Forests and Rangelands, Agricultural Research, Education and Extension Organization (AREEO), Tehran, Iran

\section{Introduction}

Hyrcanian uneven-aged mixed forests are located on the southern margin of the Caspian Sea and north of Alborz Mountain, where they cover an area of $55,000 \mathrm{~km}^{2}$ and are of great importance for maintaining the biodiversity in this part of the world (Sagheb Talebi et al. 2014). Forestry that intends to maintain this biodiversity must be based on robust predictions of forest volume growth at the stand scale that guide sustainable forest management.

Management decisions influence forest growth and yield (Gardingen et al. 2006) and generally follow the principles of sustainable forest production to ensure that cutting does not exceed the actual forest growth (Sterba 2002). Periodic change in volume is a key estimate of forest productivity, 
is the foundation of many forest growth and yield models (Sun, 2007; Thakur et al. 2019), and is essential for determining the sustainable allowable cut in uneven-aged forest management to ensure the conservation of biological diversity, forest health, and the long-term sustainability of forests (Bayat et al. 2013). A thorough understanding of volume increment enables successful stand projections and the development of appropriate management (harvesting) plans and conservation measures (Miller et al. 2005) based on rational and scientifically sound criteria (Sinha et al. 2017). Typically, methods that most accurately estimate stand volume growth with a minimum number of independent variables enjoy the greatest robustness and utility (Vieira et al. 2018).

Due to the usually high costs associated with timeconsuming fieldwork required for data collection and the remoteness of some forest areas, indirect methods for quantifying growth and productivity of forests are quite appealing (Leak 2011). Examples of some of these indirect methods are regression models, machine learning technologies, and the use of environmental, climatic, and topographic constraints for quantifying growth (Davis et al. 2001; Bourque and Bayat 2015; Bourque et al. 2019). Indeed, the use of models is a quick, easy, inexpensive, and reliable way of quantifying complex dynamics in ecological state variables (Eskelson et al. 2009; Breidenbach et al. 2010; Yu et al. 2010). Machine learning technologies that employ a set of statistical and modeling approaches have recently proven their utility for identifying latent patterns and relationships in databases. Organizations that can collect and maintain a wide range of information at low costs can spearhead the use of machine learning technologies to bring significant valueadded services and products to the organization (Hilbert and Ostendorf 2001, Ingram et al. 2005). Approaches available for machine learning are diverse and a few of these hold promise for applications in forestry are described below.

Different growth and yield modeling approaches have been pursued for predicting forest dynamics. Whereas process-based models incorporate fundamental cause and effect relationships that control tree growth and can therefore simulate growth processes even when growing conditions vary over time, such models are rarely used in management because of their high level of complexity and intensive data requirement (Ashraf et al. 2012). In contrast, empirical growth and yield models, which may be potentially biased when the environment or the management regime changes rapidly, remain popular with government departments and forest companies that estimate yield as a function of current tree dimensions, stand density, and site quality (Ashraf et al. 2012). While empirical models have traditionally been developed using regression techniques, including mixed regression models, artificial neural networks (ANNs) may constitute an alternative approach to develop more robust models than traditional regression approaches.

ANNs form a subset of artificial intelligence (AI) that are used for a wide range of problem-solving tasks, including in communication memory, optimization, prediction, diagnosis, and control (Reis et al. 2016; Vieira et al. 2018; Bayat et al. 2020). The structure and function of ANNs mimic the neurons in the human brain and consist of a few simple structural components with complex connections (Strobl and Forte 2007). In forestry, ANNs are often used to solve complex multivariate problems (Maier and

Support vector machines (SVMs) are considered the most powerful and accurate in their ability to solve problems. This method is based on classification and regression theory of statistical learning developed by Vapnik et al. (1963, 1964). In general, SVMs focus on the boundary between classes. Input space created by independent variables is covered by linear or nonlinear transformations that are based on core functions, including lower- and higher-order polynomials, radial base (RBF), and sigmoidal functions. The SVM algorithm tries to find a throw page (i.e., splitter superpage with the maximum distance from the margin points) that can accurately predict the distribution of data (Wang et al. 2009). The support vector machine has been used in many studies such as in the estimation of forest structure (Lee et al. 2018) and estimation of forest characteristics (Shataee et al. 2012).

Random forest (RF) is a nonparametric method developed as an extension of the classification and regression trees method (i.e., CART; Breiman 2001). This method can be used for a variety of regression problems and prediction of forest-dependent variables (Watts and Lawrence 2008; Walton 2008; Eskelson et al. 2009; Breidenbach et al. 2010; Yu et al. 2010). Another popular classification technique in forestry applications (e.g., Holmstrom and Fransson 2003) is based on nearest neighbor (NN) analysis, which generates and applies classification rules through training samples, without requiring additional information.

The main objective of this study was to predict net annual stand volume increment as the preeminent factor of forest growth and yield models. Taking advantage of the capabilities of modern machine learning techniques, we estimated net annual stand volume increment using the machine learning techniques of ANN, SVM, RF, and NN and compared these estimates with those derived from the traditional estimation and modeling approaches. 


\section{Materials and methods}

\subsection{Study area}

The study was done in the Jojadeh section of the Farim Forest that is located in the Mazandaran province in the southern part of Sari City on the slopes of the northern Alborz Mountains (Dodangeh district) (Fig. 1). The section covers about 3550 ha with elevations that range from 782 to $1750 \mathrm{~m}$ above mean sea level (AMSL). The regional climate is classified as humid based on the Ivanov method (Hamidi et al. 2019). Favorable climatic conditions coincide with the passage of Mediterranean airmasses from the west and Siberia and the Caspian Sea from the north that provide an annual rainfall of about $833 \mathrm{~mm}$ and an average annual temperature of about $11.2{ }^{\circ} \mathrm{C}$. The close to nature forest management process implemented in northern Iran is a combination of the single tree and group selection systems in which about $2.5 \%$ of the standing volume is removed per year, which has led to the development of a typical
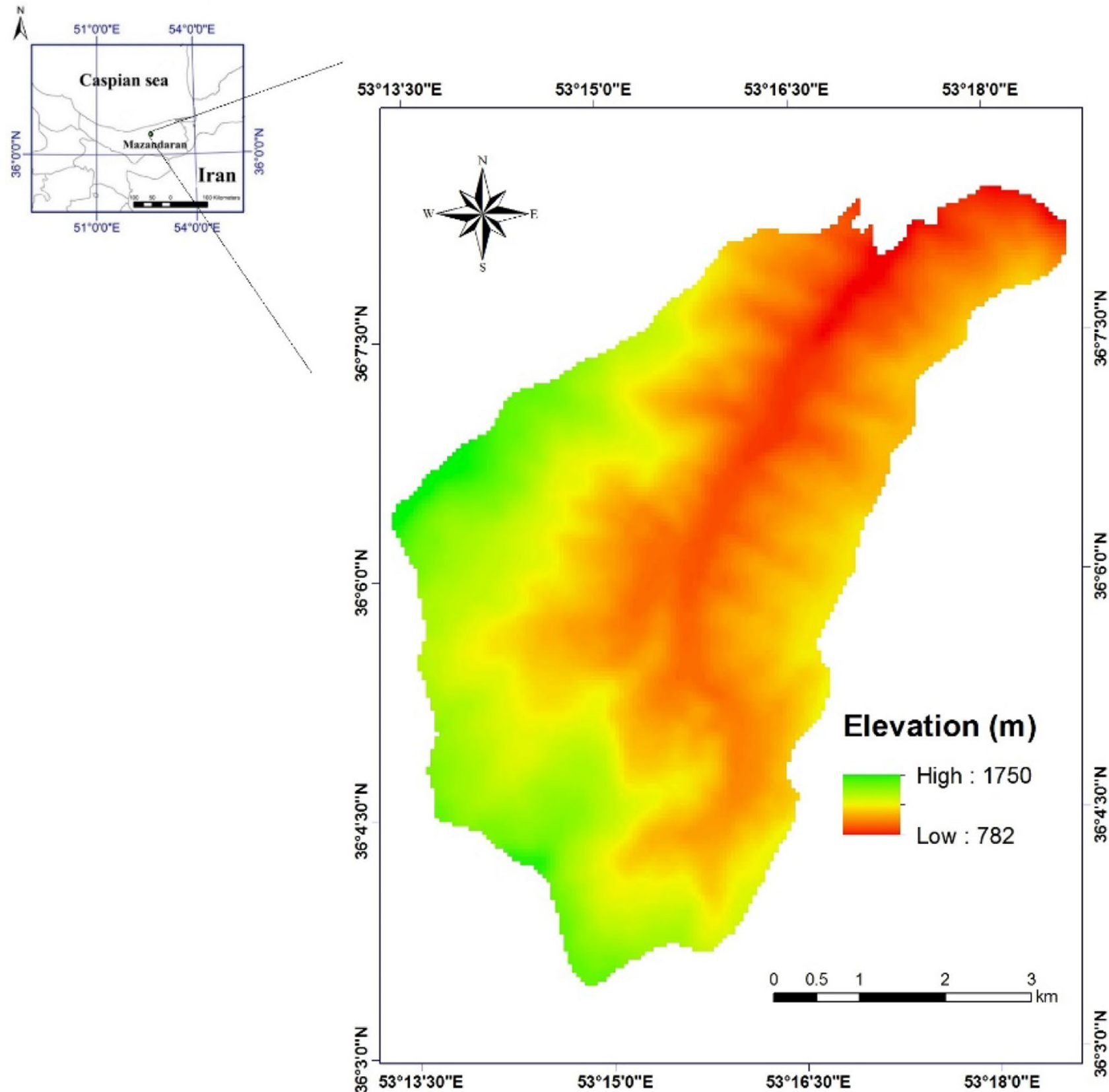

Fig. 1 Location of the study area in northern Iran. Variations in color indicate different elevations (m, AMSL; see legend) 
heterogeneous, uneven-aged, mixed forest within the study area. The study area was comprised of the following tree species that were shade tolerant to intermediately shadetolerant and comprised the vast majority of the standing volume: Oriental beech (Fagus orientalis Lipsky, 60\%), European hornbeam (Carpinus betulus L. 15\%), Caucasian alder (Alnus subcordata C.A. Mey., 11\%), and Velvet maple (Acer velutinum Boiss., 7\%) (Hamidi et al. 2016).

\subsection{Study methods}

In 2003,313 circular inventory plots ( $0.1 \mathrm{ha}$, each) were systematically laid out on an inventory grid $(200 \mathrm{~m} \times$ $150 \mathrm{~m}$ ). Due to steep north-facing slopes, the directions of the grid axes were set north-to-south and east-towest, allowing the surveyors to walk along the contours of the land. Slope corrections were applied to plot radii measured along the soil surface to obtain horizontal plot areas of precisely 0.1 ha. Plot centers were monumented with a pole during the first measurement period. All trees were numbered with paint for identification at later inventories, and the position of the DBH was permanently marked on each tree.

In each plot, the diameter at breast height (DBH) of all trees with a DBH $>12.5 \mathrm{~cm}$ was measured with calipers in 2003 and 2013 and it was recorded whether each tree was alive or dead. New ingrowth trees were added in 2013 if they passed the $12.5 \mathrm{~cm}$ minimum DBH threshold. Physiographic factors, including slope, aspect, and elevation, were fieldverified and recorded for each plot.

After data entry, basal areas and volumes in 2003 and 2013 were computed for each tree, summed to the plot level, and extrapolated to the hectare level. For each plot, volumes of live and dead trees as well as harvested volumes were computed. In addition, the square of the basal area of 2003 was computed, and slope, aspect, elevation, temperature, and precipitation data were compiled. Temperature and precipitation data were interpolated from records obtained in the three closest climate stations (Pol-e Sefid, Alasht and Kiasar), giving the greatest weight to data from the closest station. The 10-year net annual volume change or periodic annual volume increment $\left(\mathrm{PAI}_{\mathrm{VOL}}\right)$ between 2003 and 2013 was calculated as

$\mathrm{PAI}_{\mathrm{VOL}}=\left(V_{E}+V_{H}-V_{B}\right) / 10$

where $\mathrm{PAI}_{\mathrm{VOL}}$ is the net annual volume change over 10 years, $V_{E}$ is the volume at the end of the measurement period (2013), $V_{H}$ is the average of volume that was harvested or died across all plots during the same period, and $V_{B}$ is the volume at the beginning of the measurement period (2003).
In this study, stem volumes of a total of 4832 trees for which a diameter was measured were estimated using official tariff (volume) tables that were converted into the following volume functions by species (Bayat et al. 2013):

Fagus orientalis $: v=0.0001000 \mathrm{DBH}^{2.503}$

Carpinus betulus : $v=0.0000999 \mathrm{DBH}^{2.470}$

Other species $: v=0.0002996 \mathrm{DBH}^{2.273}$

where $v$ is the stem volume $\left(\mathrm{m}^{3}\right)$ and DBH is the diameter at breast height $(\mathrm{cm})$.

Once net annual volume change between 2003 and 2013 was computed, the following general estimation workflow of the machine learning and statistical methods that show different inputs, processes, variables, and outputs were pursued (Fig. 2). Following data collection and identification of the dependent and independent variables, the data were analyzed by one statistical method (i.e., least squares regression analysis) and four different machine learning methods. In three of the four machine learning methods, different algorithms were explored to find the best model (a more detailed explanation is given in the following sections).

The potential parameters to the volume increment model $\left(\mathrm{PAI}_{\mathrm{VOL}}\right)$ included a measure of competition (quantified as basal area (BA) and basal area squared $\left(\mathrm{BA}^{2}\right)$; Vanclay 1994) and several physiographic (aspect (ASP), slope (SLP), elevation (ELE)) and climatic variables (temperature (TEMP), precipitation (PRE)). The stepwise selection (or sequential replacement) procedure was used to select statistically significant independent variables. Regression analysis was used to model the 10-year net annual volume increment $\left(\mathrm{PAI}_{\mathrm{VOL}}\right)$ (Lhotka, and Loewenstein, 2011, Heshmatol Vaezin et al. 2008, Schroder et al. 2002) as:

$$
\begin{aligned}
\mathrm{PAI}_{\mathrm{VOL}} & =\gamma+\beta \mathrm{BA}+\alpha \mathrm{BA}^{2}+\varphi \cdot \mathrm{ASP} \\
& +\rho \cdot \mathrm{SLP}+\omega \cdot \mathrm{ELE}+\chi \cdot \mathrm{TEMP}+\nu \cdot \mathrm{PRE})
\end{aligned}
$$

where $\gamma, \lambda, \beta, \alpha, \varphi, \rho, \omega, \chi$, and $v$ are the model parameters that were estimated with regression analysis.

Four machine learning algorithms (i.e., ANNs, SVMs, RF, and $\mathrm{NN}$ ) were tested in the current study. The salient features of the various machine learning methods are as follows:

1. ANNs used in this study consisted of two common architectures, one based on the feed-forward multilayer perceptron (MLP) and one on the radial basis function (RBF). The MLP- and RBF-based ANNs with backpropagation are the most used in solving difficult engineering problems (Walling et al. 2001; Zhu et al. 2007). The methods provide robust estimates (Reis et al. 2018; 
Fig. 2 The workflow employed in this study to develop the model of volume change using a statistical (regression) method and machine learning methods

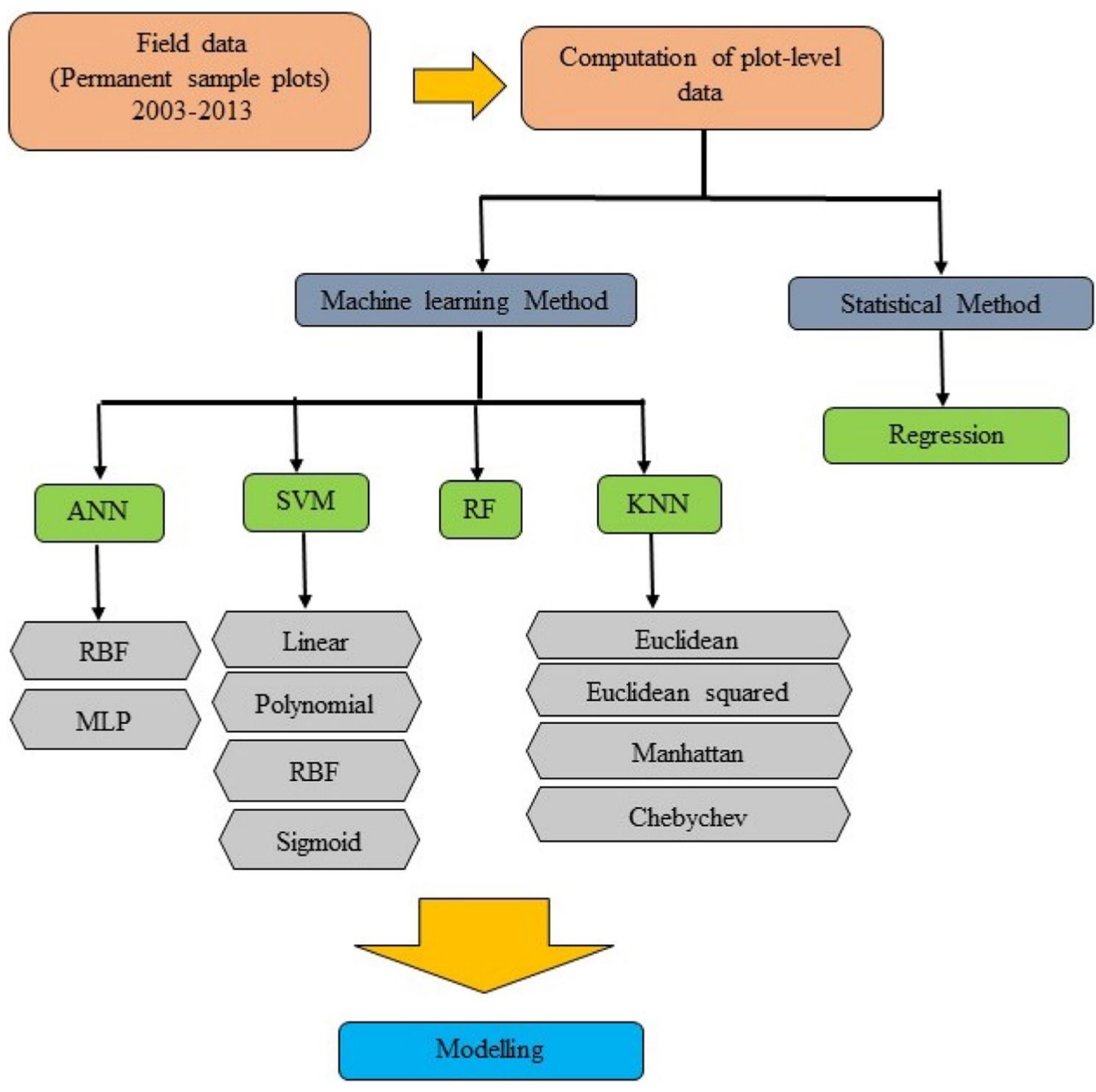

Bayat et al. 2019a) and give approximations to all sorts of nonlinear functions (Benali et al. 2019). These ANNs were trained with back-propagation algorithms, using a random subset of $70 \%$ of the input-output data records for model training and the rest for testing (Hilbert et al. 2001; Benali et al. 2019). Prior to training, all input and output data were normalized (Nagy et al. 2002; Van Dao et al. 2020). The ANN structure was iteratively altered by changing the number of hidden nodes. The structure that produced the least amount of error (i.e., the difference between modeled and observed values) was selected for testing at a later stage.

2. SVM is a nonparametric, supervised statistical method that is a binary classifier (Mountrakis et al. 2011). In creating an associated model, the kernel type must be selected, and the number of kernel parameters needs to be determined (Shataee et al. 2012). In this study, four kernel types were examined, including a linear, polynomial, RBF-based, and sigmoidal type (Vafaei et al. 2018). The kernel parameters include capacity $(c)$, gamma $(\gamma)$, and epsilon $(\varepsilon)$. To evaluate the model fits, gamma values were calculated as 1 divided by number of independent variables (Hsu et al. 2010). For selecting the best parameters, capacity, and epsilon rates, a tenfold cross-validation with 1000 iterations for minimizing the error function (Schölkopf et al. 2000) through a specified grid search method (Hsu et al. 2010) was used. The specified grid search included a range of capacity from 1 to 50 , which is equal to the range of input variables (Mattera and Haykin 1999); epsilon rates varied from 0.1 to 0.5. Internally, the SVM calculates the model not with a simple formula but optimizes the model stepwise. The strictness of this optimization is controlled by the capacity and epsilon parameters.

3. RF is a group of algorithms that use a set of decision trees for classification and prediction (Dietterich 2000). Decision trees represent rules, which can be easily understood and used in knowledge systems such as databases. A decision tree is a hierarchical model for supervised learning whereby local regions are identified in a sequence of recursive splits in a small number of steps. A decision tree is composed of internal decision nodes and terminal leaves. Based on our input data, we created five nodes and used 300 initial trees for training and testing to produce a graph that shows the average squared error rate against each tree. One of the main 
parameters that must be set is the $k$-predictor for each node. The simplest way to determine $k$ is to calculate the square root of the total number of independent variables, i.e., $k \leq \sqrt{ } n$, where $n$ is number of input variables.

4. The kNN method categorizes a point according to its nearest neighbors. The $k$-graph of $\mathrm{NN}$ is the point on the graph that is connected to its nearest neighbor. The degree of similarity is based on a distance metric based on Euclidean, Euclidean squared, Manhattan, or Chebychev distances calculated for selected attributes. The number of neighbors used depends on the type of data. The number of optimal neighbors is typically between 5 and 10 (e.g., Kutzer 2008; Gu et al. 2006; Reese et al. 2002; Sanquetta et al. 2015) but can be as high as 50 (e.g., Finely et al. 2006).

Among the models with different kernels, the supportFor each model, we first randomly selected $70 \%$ of the data for training and $30 \%$ for validation/testing (see also Bayat et al. 2019a; Benali et al. 2019). Common criteria for assessing the goodness-of-fit of model predictions have historically been the coefficient of determination $\left(R^{2}\right)$, the root-mean-squared error (RMSE), the relative RMSE, BIAS, and the relative BIAS (Lumbres et al. 2016). An important advantage of the relative RMSE (in \%) is that it enables comparisons among predictions produced by different models (Pulido-Calvo et al. 2007).

$\mathrm{RMSE}=\sqrt{\frac{\sum_{i=1}^{n}\left(\mathrm{est}_{i}-\mathrm{obs}_{i}\right)^{2}}{n}}$

relative $\mathrm{RMSE}=100 *(\mathrm{RMSE} /$ mean observation value $)$

$\mathrm{BIAS}=\frac{\sum_{i=1}^{n}\left(\mathrm{es}_{i}-\mathrm{obs}_{i}\right)}{n}$

Relative BIAS $=100 *(\mathrm{BIAS} /$ mean observation value $)$

where est ${ }_{i}$ and obs ${ }_{i}$ are the $i$ th estimate and observation, respectively, and $n$ is the number of observations.

\section{Results}

\subsection{Stand metrics}

In general, the mean values of DBH, BA, and volume covered a broad range of conditions and consistently increased between 2003 and 2013 (Table 1).

Between 2003 and 2013, an average volume of $5.7 \mathrm{~m}^{3} \mathrm{ha}^{-1}$ year $^{-1}$ was harvested and $2.0 \mathrm{~m}^{3} \mathrm{ha}^{-1}$ year $^{-1}$ died across all plots. Figure 3 shows how harvest and natural morality was divided among different tree size classes of trees.

\subsection{Regression analysis}

Net annual volume increment per hectare was $2.36 \mathrm{~m}^{3} \mathrm{ha}^{-1}$ year $^{-1}\left(\mathrm{SE}=0.07 \mathrm{~m}^{3} \mathrm{ha}^{-1}\right.$ year $\left.^{-1}\right)$ and ranged between 0.15 and $7.58 \mathrm{~m}^{3} \mathrm{ha}^{-1}$ year ${ }^{-1}$. Average basal area across the study area was $23.08 \mathrm{~m}^{2} \mathrm{ha}^{-1}\left(\mathrm{SE}=0.55 \mathrm{~m}^{2} \mathrm{ha}^{-1}\right)$ and ranged between 1.18 and $54.05 \mathrm{~m}^{2} \mathrm{ha}^{-1}$. There was a mild curvilinear relation between 10-year net annual volume increment and basal area that was best captured by the following regression model Eq. (7).

$\mathrm{PAI}_{\mathrm{VOL}}=0.123+0.082(\mathrm{BA})+0.0006\left(\mathrm{BA}^{2}\right)$

where $\mathrm{PAI}_{\mathrm{VOL}}$ is the net annual volume increment $\left(\mathrm{m}^{3}\right.$ $\left.\mathrm{ha}^{-1}\right)$ and BA is the basal area $\left(\mathrm{m}^{2} \mathrm{ha}^{-1}\right)$ in 2003.

None of the physiographic or climatic variables were statistically significantly related to net annual volume increment. BA $(t=7.18, p<0.001)$ and $\mathrm{BA}^{2}(t=2.45, p=0.015)$ were statistically significant, resulting in an $R^{2}$ of 0.81 , a root-meansquared error of $0.52 \mathrm{~m}^{3} \mathrm{ha}^{-1}$, and residual standard error of $0.27 \mathrm{~m}^{3} \mathrm{ha}^{-1}$. The relative RMSE was $22.0 \%$. The residuals showed a slight positive bias (under-estimate of growth) in plots where volume increment exceeded $4.5 \mathrm{~m}^{3} \mathrm{ha}^{-1}$ year $^{-1}$ (Fig. 4a). No bias was observed with basal area (Fig. 4b).

Table 1 Mean, maximum, minimum, and standard deviation (STD) of basic stand descriptors

\begin{tabular}{|c|c|c|c|c|c|c|c|}
\hline Variable & $\begin{array}{l}\text { TPHA } 2003(\# \\
\left.\mathrm{ha}^{-1}\right)\end{array}$ & DBH $2003(\mathrm{~cm})$ & DBH $2013(\mathrm{~cm})$ & $\begin{array}{l}\text { BA } 2003\left(\mathrm{~m}^{2}\right. \\
\left.\mathrm{ha}^{-1}\right)\end{array}$ & $\begin{array}{l}\text { BA } 2013 \\
\left(\mathrm{~m}^{2} \mathrm{ha}^{-1}\right)\end{array}$ & $\begin{array}{l}\text { Volume } 2003 \\
\left(\mathrm{~m}^{3} \mathrm{ha}^{-1}\right)\end{array}$ & $\begin{array}{l}\text { Volume } \\
2013 \\
\left(\mathrm{~m}^{3} \mathrm{ha}^{-1}\right)\end{array}$ \\
\hline Mean & 154 & 41.08 & 43.15 & 23.07 & 25.14 & 226.73 & 250.34 \\
\hline Maximum & 500 & 88.00 & 91.46 & 54.04 & 57.98 & 685.41 & 749.11 \\
\hline Minimum & 30 & 13.29 & 15.16 & 1.17 & 1.44 & 8.20 & 10.17 \\
\hline Std. deviation & 74.42 & 12.86 & 13.29 & 9.70 & 10.48 & 109.89 & 120.54 \\
\hline
\end{tabular}


Fig. 3 Average annual harvest volumes and mortality $\left(\mathrm{m}^{3} \mathrm{ha}^{-1}\right.$ year $\left.^{-1}\right)$ by diameter class $(\mathrm{cm})$ between 2003 and 2013

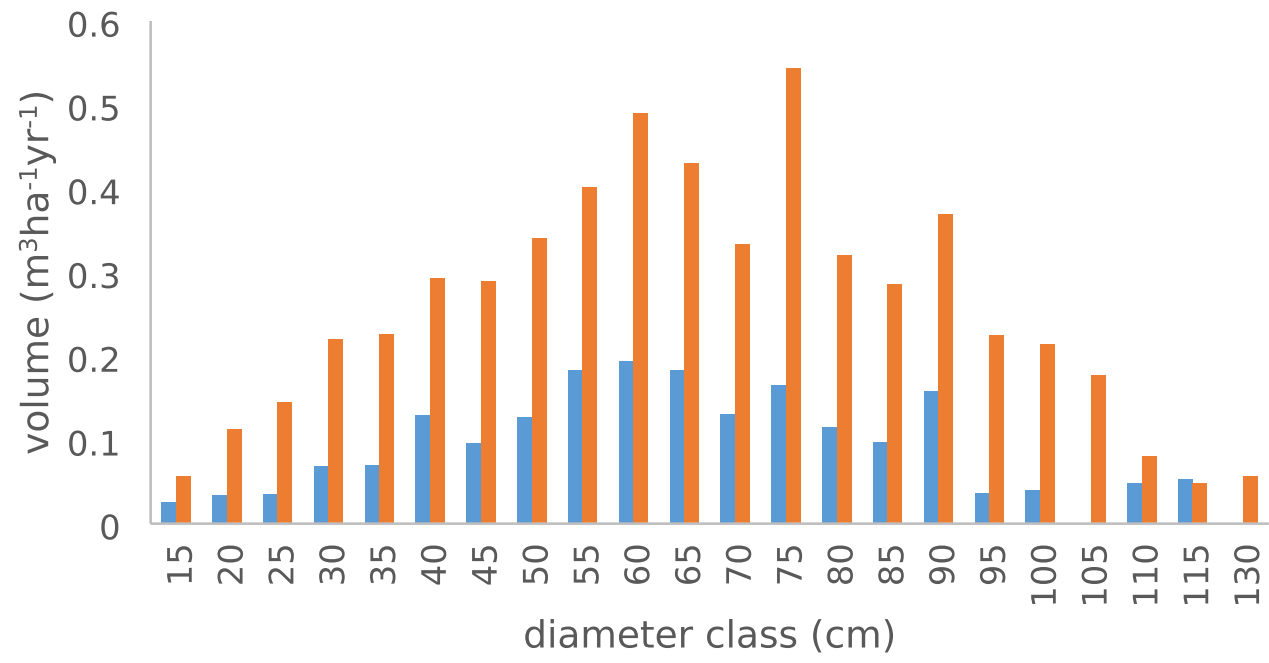

ndied $\square$ harvest

\subsection{Machine learning methods}

\subsubsection{Artificial neural network}

The neural network structure consisted of a multi-input layer, a hidden multi-layer, and an output layer, with a minimum 5 and a maximum 12 layers (Table 2). The independent variables of $\mathrm{BA}, \mathrm{BA}^{2}$, slope, aspect, and elevation were input layers, and the dependent variable of net annual volume increment per hectare was the output layer. For each of the MLP- and RBF-based ANNs, five models were examined. MLP-based ANNs gave superior results over RBF-based models for both training and evaluation datasets, with $R^{2}$ values of 0.93 for MLP and 0.90 for RBF (Tables 2 and 3), indicating that a strong relation existed between the actual measured standing volume and the predicted volume by the MLP (Fig. 5).

$\mathrm{BA}$ and $\mathrm{BA}^{2}$ were the most important predictor values for estimating net annual volume increment, followed by precipitation and elevation (Fig. 5).
Similar to the least-squares analysis, the residuals showed a slight positive bias (under-estimate of growth) in plots where volume increment exceeded $4.5 \mathrm{~m}^{3} \mathrm{ha}^{-1}$ year $^{-1}$ (Fig. 6a). No bias was observed with basal area (Fig. 6b).

\subsubsection{Support vector machine}

Among the models with different kernels, the support vector machine method with an RBF Gamma kernel produced the smallest RMSE in both the training and evaluation models (Table 4).

The sum of the weight characteristics of each of the variable support vectors are as follows: BA (42.21), $\mathrm{BA}^{2}$ (37.12), precipitation (29.34), temperature (25.15), elevation (24.27), slope (20.71), and aspect (12.65). Similar to the previous analyses, the residuals showed a slight positive bias (under-estimate of growth) in plots where volume increment exceeded $4.5 \mathrm{~m}^{3} \mathrm{ha}^{-1}$ year $^{-1}$ (Fig. 7a). No bias was observed with basal area (Fig. 7b).
Fig. 4 Model residuals of net annual volume increment plotted against observed net annual volume increment $\left(\mathrm{m}^{3} \mathrm{ha}^{-1}\right.$ year $\left.^{-1}, \mathbf{a}\right)$ and basal area $\left(\mathrm{m}^{2} \mathrm{ha}^{-1}, \mathbf{b}\right)$ based on least squares regression analysis
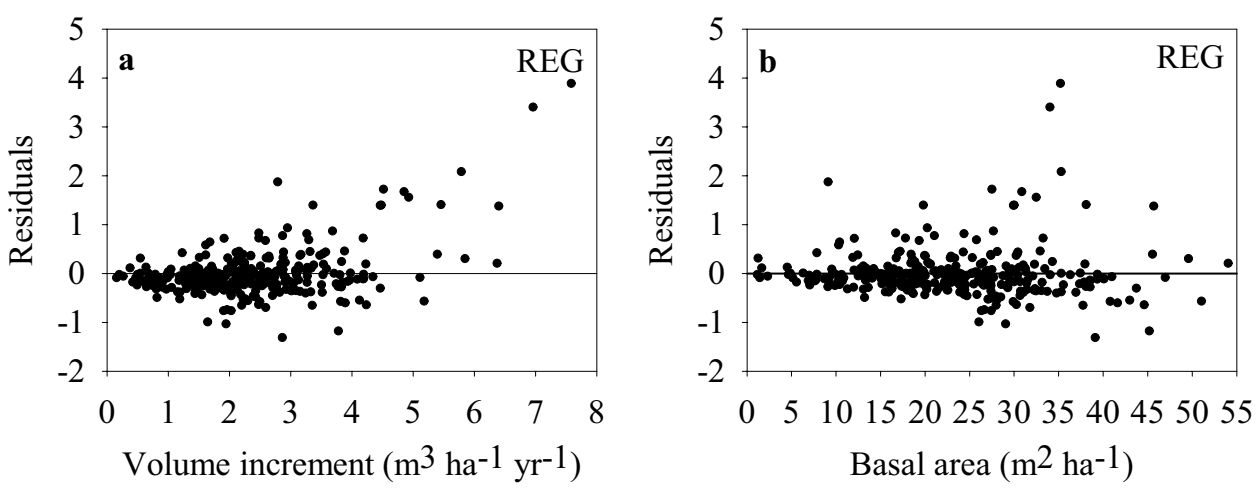
Table 2 Characteristics of RBF and MLP-based ANNs and associated metrics for model training

\begin{tabular}{llllllllll}
\hline Index & Structure & Algorithm & Error function & Hidden activation & $R^{2}$ & RMSE & \%RMSE & BIAS & \%BIAS \\
\hline 1 & MLP 7-12-1 & BFGS 11 & SOS & Logistic & 0.908 & 0.5029 & 20.867 & 0.0011 & 0.0047 \\
2 & MLP 7-5-1 & BFGS 14 & SOS & Identity & 0.908 & 0.5020 & 20.832 & 0.0468 & 0.1971 \\
3 & MLP 7-9-1 & BFGS 11 & SOS & Identity & 0.908 & 0.5020 & 20.832 & 0.0011 & 0.0047 \\
4 & MLP 7-10-1 & BFGS 16 & SOS & Identity & 0.907 & 0.5041 & 20.917 & 0.0468 & 0.1971 \\
5 & MLP 7-11-1 & BFGS 11 & SOS & Tanh & 0.911 & 0.4945 & 20.52 & 0.0009 & 0.0016 \\
6 & RBF 7-24-1 & RBFT & SOS & Gaussian & 0.854 & 0.624 & 25.893 & 0.0010 & 0.0020 \\
7 & RBF 7-30-1 & RBFT & SOS & Gaussian & 0.895 & 0.534 & 22.179 & 0.0450 & 0.0863 \\
8 & RBF 7-27-1 & RBFT & SOS & Gaussian & 0.865 & 0.601 & 24.950 & 0.0010 & 0.0020 \\
9 & RBF 7-30-1 & RBFT & SOS & Gaussian & 0.877 & 0.576 & 23.905 & 0.0450 & 0.0863 \\
10 & RBF 7-29-1 & RBFT & SOS & Gaussian & 0.810 & 0.704 & 29.213 & 0.0010 & 0.0020 \\
\hline
\end{tabular}

\subsubsection{Random forest}

Based on the graph of squared error variation with increasing numbers of trees in the training and validating/ testing dataset, the number of optimal trees for modeling net annual volume increment $\left(\mathrm{m}^{3} \mathrm{ha}^{-1}\right.$ year $\left.{ }^{-1}\right)$ was estimated at 250 trees (Fig. 8). To find the optimal number of trees for volume modeling, the error square of the error diagram was evaluated with an increasing number of trees in both for training and testing datasets. The optimal number of trees is the point on the curve when further increases no longer reduce the error square diagram, which was reached at 250 trees. The optimal number of trees in a random forest depends on the number of predictors. If the chosen number of trees is too small, however, then some observations will be predicted only once or even not at all and some features can (theoretically) be missed in all subspaces used, resulting in decreased predictive power of the random forest model. Thus, a greater number of trees chosen typically results in better model outcomes.

Decision trees are powerful and popular tools for classification and prediction. In contrast to neural networks, the attractiveness of decision trees is that they represent clear rules that are easy to interpret. Each box in the tree in Fig. 8 represents a node. A decision tree grows from the top node, called the root node downward and splits the data at each level to form new nodes. The resulting tree comprises many nodes connected by branches. Nodes that are at the end of branches are called leaf nodes and play a special role when the tree is used for prediction. In Fig. 8 each node contains information about the number of instances $(N)$ at that node and about the distribution of the values of the dependent variable. The instances at the root node are all of the observations in the training set $(N=120)$. Below the root node (parent, comprised by BA) is the first split that, in this case, splits the data into two new nodes (children) based on the predictor balance of current account. The decision tree derived from the random forest classification method has 9 non-terminal children and 10 terminal nodes (Fig. 9) and includes the two most important decision variables of BA (importance $=1.0$ ), $\mathrm{BA}^{2}$ (importance $\left.=0.95\right)$, slope $(0.13)$, elevation $(0.11)$, precipitation (0.10), temperature (0.09), and aspect (0.08). Also, based on the above results, modeling with seven variables in each node $(k=7)$ resulted in a minimum of

Table 3 Characteristics of RBF and MLP-based ANNs and associated metrics for model evaluation

\begin{tabular}{|c|c|c|c|c|c|c|c|c|c|}
\hline Index & Structure & Algorithm & Error function & Hidden activation & $R^{2}$ & RMSE & $\%$ RMSE & BIAS & $\%$ BIAS \\
\hline 1 & MLP 7-12-1 & BFGS 11 & SOS & Logistic & 0.928 & 0.24 & 10.81 & 0.011 & 0.5394 \\
\hline 2 & MLP 7-5-1 & BFGS 14 & SOS & Identity & 0.930 & 0.21 & 9.451 & 0.016 & 0.7316 \\
\hline 3 & MLP 7-9-1 & BFGS 11 & SOS & Identity & 0.930 & 0.21 & 9.451 & 0.014 & 0.6685 \\
\hline 4 & MLP 7-10-1 & BFGS 16 & SOS & Identity & 0.926 & 0.24 & 10.810 & 0.007 & 0.3391 \\
\hline 5 & MLP 7-11-1 & BFGS 11 & SOS & Tanh & 0.936 & 0.19 & 8.558 & 0.004 & 0.2021 \\
\hline 6 & RBF 7-24-1 & RBFT & SOS & Gaussian & 0.862 & 0.29 & 13.063 & 0.009 & 0.3132 \\
\hline 7 & RBF 7-30-1 & RBFT & SOS & Gaussian & 0.893 & 0.25 & 10.810 & 0.023 & 1.0520 \\
\hline 8 & RBF 7-27-1 & RBFT & SOS & Gaussian & 0.861 & 0.28 & 12.6126 & 0.039 & 1.7651 \\
\hline 9 & RBF 7-30-1 & RBFT & SOS & Gaussian & 0.858 & 0.26 & 11.711 & 0.006 & 0.2926 \\
\hline 10 & RBF 7-29-1 & RBFT & SOS & Gaussian & 0.901 & 0.27 & 12.162 & 0.018 & 0.852 \\
\hline
\end{tabular}




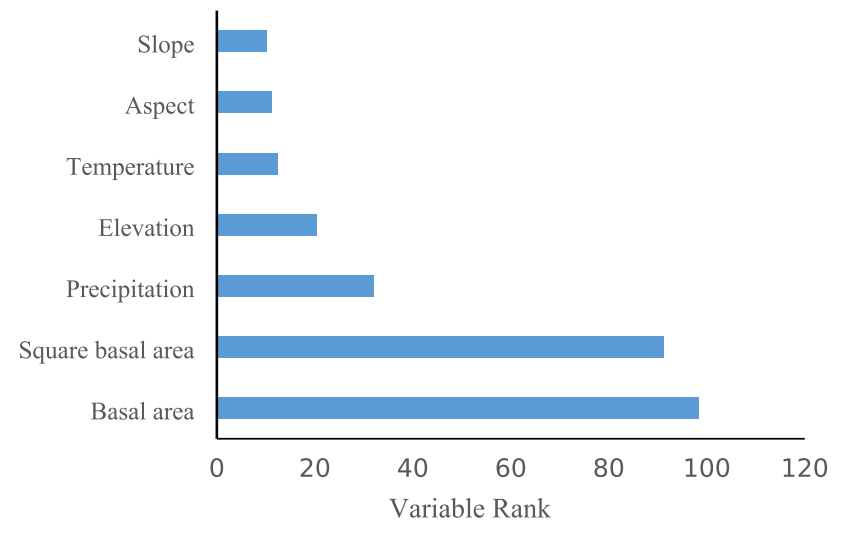

Fig. 5 Relative importance of predictor variables in the ANN model for estimating net annual volume increment

RMSE and was selected as optimal $K$ for estimating the net annual volume increment.

The net annual volume increment model using the Random Forest method had an $R^{2}$ of 0.89 , with a RMSE of $0.52 \mathrm{~m}^{3} \mathrm{ha}^{-1}$, a BIAS of $0.03 \mathrm{~m}^{3} \mathrm{ha}^{-1}$, a relative RMSE of $22.2 \%$, and a relative BIAS of $1.4 \%$. In contrast to the previous methods, the residuals showed a clear bias, over-estimating net annual volume increment in plots with low growth rates and under-estimate volume increment in plots with growth rates above $4 \mathrm{~m}^{3} \mathrm{ha}^{-1}$ year $^{-1}$ (Fig. 10a). This bias was less clear but nonetheless present with basal area as well (Fig. 10b).

\subsubsection{Nearest neighbor algorithm}

The nearest neighbor algorithm weighed with a range of 1 to 20, and each of four distance metrics (i.e., Euclidean, Euclidean squared, Manhattan and Chebychev distances) showed that the Manhattan distance metric with $K=11$ neighbors resulted in the least RMSE and bias for both training and evaluation datasets (Table 5). Even with the best model, the relationship between estimated and observed net annual volume increment was modest, resulting in an $R^{2}$ of 0.75 .
Compared with the previous methods, the residuals showed no bias with either net annual volume growth rates (Fig. 11a) or basal area (Fig. 11b). However, the range of negative residuals is greater than for the previous methods, which were generally less than -1.5 .

A comparison of the fitted models of net annual volume increment $\left(\mathrm{m}^{3} \mathrm{ha}^{-1}\right.$ year $\left.^{-1}\right)$ as a function of basal area $\left(\mathrm{m}^{2} \mathrm{ha}^{-1}\right)$ shows that all of the evaluated models depicted very similar relationships between these two variables. All methods depict a slightly curvilinear relationship between net annual volume increment and basal area, as evidenced by the significance of $\mathrm{BA}^{2}$ in each model (Fig. 12). As a consequence, differences in the quality of the model (i.e., coefficient of determination, RMSE, and relative RMSE) outcomes is largely due to each model's ability to use additional information contained in the physiographic factors to refine the model.

A comparison of the coefficients of determination, RMSEs, and relative RMSEs of the different estimation methods shows that the ANN and SVM methods resulted in the best models, with a slight superiority of the ANN method over the SVM method (Table 6). The models derived from the random forest and the statistical (least-squares regression) methods resulted in models providing lesser fits, with RMSEs that were 3-4 times larger than the ANN model. The $\mathrm{kNN}$-algorithm resulted in the poorest model fit based on $R^{2}$ and the greatest RMSE value of all methods that were evaluated.

\section{Discussion}

All modeling methods that predict forest performance, such as regression models and artificial intelligence models, have their own strengths and weaknesses. Although traditional regression models are capable of providing specific formulas, and these may make it easier to understand the relationships between the variables in these models, the many limitations of the regression models include stringent statistical assumptions such as the normal distribution of data, the
Fig. 6 Model residuals of net annual volume increment plotted against observed net annual volume increment $\left(\mathrm{m}^{3} \mathrm{ha}^{-1}\right.$ year $\left.^{-1}, \mathbf{a}\right)$ and basal area $\left(\mathrm{m}^{2} \mathrm{ha}^{-1}, \mathbf{b}\right)$ based on the best ANN algorithm
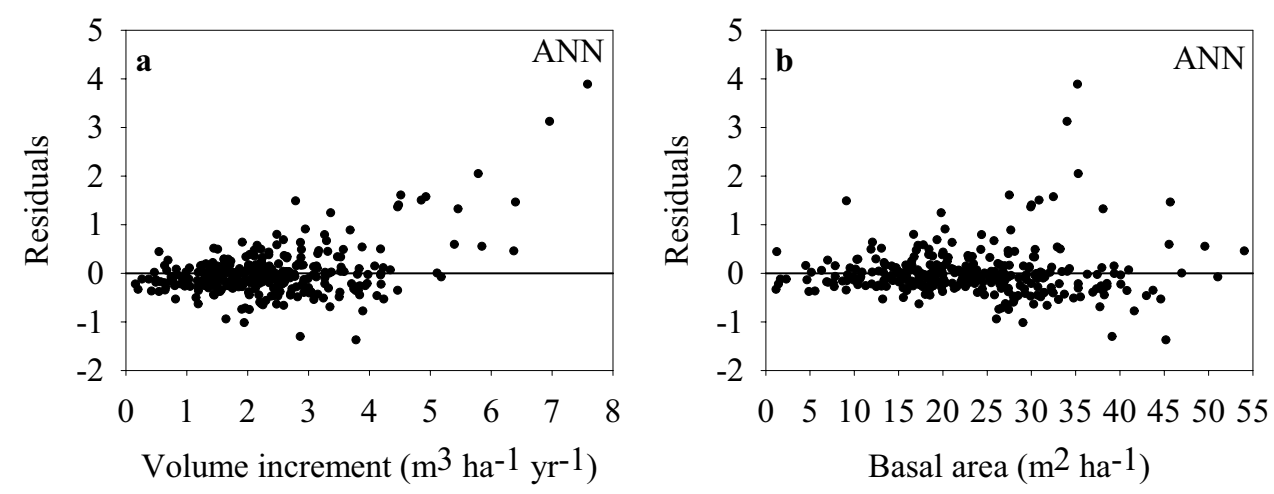
Table 4 Evaluation of SVMs based on different kernel types

\begin{tabular}{|c|c|c|c|c|c|c|c|c|}
\hline \multirow[t]{2}{*}{ Kernel type } & \multicolumn{2}{|l|}{ Linear } & \multicolumn{2}{|c|}{ Polynomial } & \multicolumn{2}{|c|}{ RBF Gamma } & \multicolumn{2}{|c|}{ Sigmoid } \\
\hline & Train & Evaluation & Train & Evaluation & Train & Evaluation & Train & Evaluation \\
\hline$R^{2}$ & 0.90 & 0.86 & 0.89 & 0.85 & 0.91 & 0.92 & 0.39 & 0.41 \\
\hline RMSE & 0.45 & 0.52 & 0.44 & 0.48 & 0.3 & 0.33 & 0.80 & 0.83 \\
\hline BIAS & 0.092 & 0.097 & 0.19 & 0.099 & 0.063 & 0.061 & 2.23 & 2.31 \\
\hline$\%$ RMSE & 28.08 & 23.83 & 18.55 & 22.06 & 12.44 & 14.93 & 33.45 & 37.41 \\
\hline$\%$ BIAS & 3.81 & 4.36 & 7.88 & 4.45 & 2.61 & 2.74 & 92.53 & 104.05 \\
\hline Gamma & - & & 0.14 & & 0.14 & & 0.14 & \\
\hline Epsilon & 0.1 & & 0.1 & & 0.1 & & 0.1 & \\
\hline Capacity & 10 & & 10 & & 10 & & 10 & \\
\hline
\end{tabular}

independence of variables, and equal variances and that, if violated, reduces the quality of empirical models (Weiskittel et al. 2011). Because we did not include, for example, nonlinear regression analysis in this study, our conclusions of the poorer performance of regression analysis compared with some machine learning techniques, is limited to traditional least-squares linear regression analysis. One of the advantages of artificial intelligence techniques in modeling is that they are not limited by strict statistical assumptions; they are able to incorporate qualitative variables, and produce relatively accurate and precise models (Viera et al. 2018; Janizadeh et al. 2019). Our results clearly demonstrate the capability of some machine learning techniques (artificial neural networks and support vector machine methods) to produce more accurate estimates of plot-level net annual volume increment in uneven-aged, mixed forests and to identify important predictors (e.g., basal area and physiographic factors such as elevation, slope, and aspect) than traditional least-squares regression. Although not all artificial neural network and machine learning algorithms performed equally well, the superiority of the ANN and SVM methods over the regression, RF, and kNN methods can be attributed to the nature of machine learning that can easily incorporate information of environmental variables into models and extract knowledge directly from data without any pre-defined assumptions of the phenomenon being investigated to significantly improve the quality of the models (Bayat et al. 2019b). In fact, the independence on initial assumptions about the input data is one of the most important features of ANN, which means that input data can assume any statistical distribution (Civco et al. 1994). This enables the use of machine learning methods for solving various problems in natural resources management and based on the results of this study, makes them an effective tool for modeling volume changes in forest growth models.

The challenge when using artificial neural networks models, however, is to find the number of hidden layers and the proper transfer functions that result in the least error between the predicted and the actual parameter. Although there is no general rule for selecting the number of hidden layer neurons yet, some researchers have suggested that this number should be equal to one more than twice the number of input neurons (input variables) (Zhu et al. 2018), even though the number of neurons obtained from this expression does not necessarily guarantee the best results or generalization of network results. Because the number of hidden layer neurons depends on the dataset and on the number and quality of training patterns, the analysis is repeated with different numbers of hidden layers until evaluation criteria indicate the number of hidden layers that resulted in the best model fit. In this study, the trial and error procedure showed that 11 hidden layers resulted in the best performance of the two
Fig. 7 Model residuals of net annual increment growth plotted against observed net annual volume increment $\left(\mathrm{m}^{3} \mathrm{ha}^{-1}\right.$ year $^{-1}$, A) and basal area $\left(\mathrm{m}^{2} \mathrm{ha}^{-1}\right.$, B) based on the best SVM algorithm
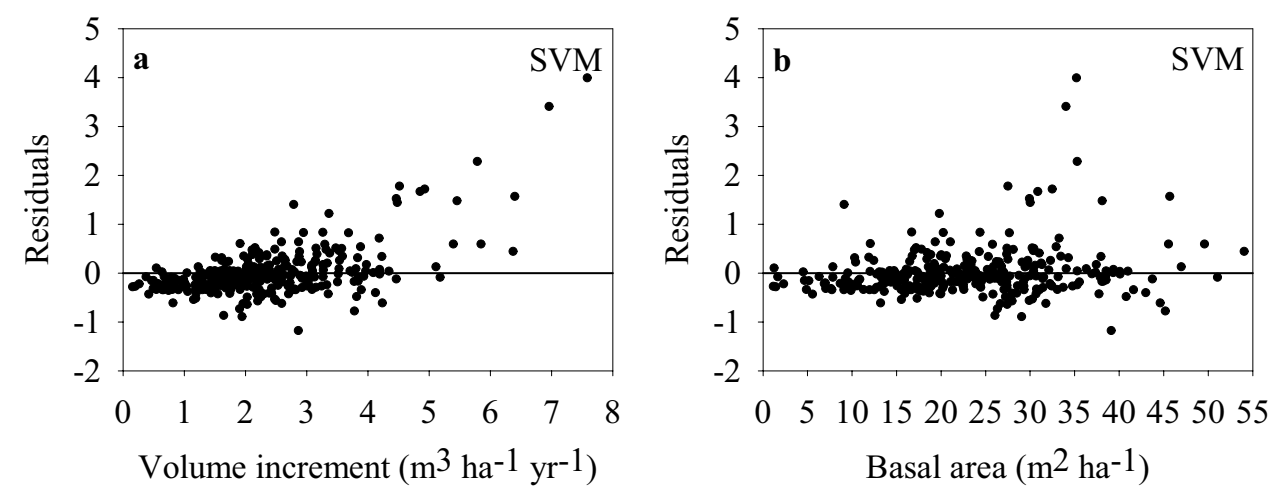
Fig. 8 Variation in mean squared error in estimating the volume relative to the number of trees

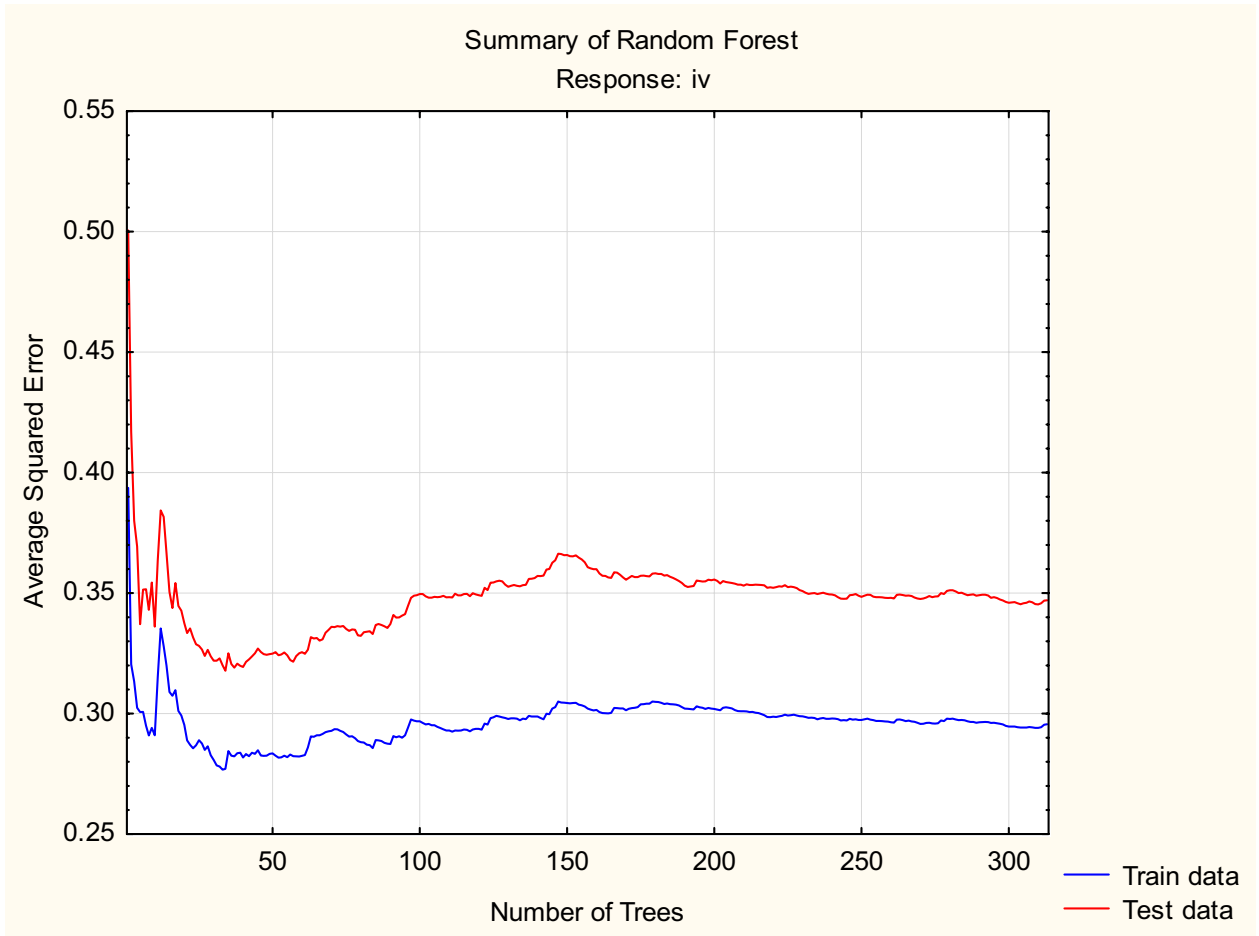

ANN algorithms that produced a robust model with our input variables that evaluated the influence of basal area and physiographic factors on net annual volume increment. For both ANN models that were tested (i.e., the MLP-based ANN and the RBF-based ANN), using more than 11 neurons in the hidden layer did not significantly improve model accuracy. This number is similar than those of a multilayer feed forward neural network that achieved the lowest RMSEs for predicting tree height and volume of Chinese fir with four and seven nodes, respectively (Huang et al. 2014). In this study, the ANN based on the multilayer perceptron network (MLP) provided a better fit to the data than the RBF-based ANN and explained $92 \%$ of the variability in the data. In both cases, $\mathrm{BA}$ and $\mathrm{BA}^{2}$ were the most influential variables whose effects were further modified by physiographic and microclimatic factors in the form of elevation, slope, and aspect. Similar to results in other studies (Toth et al. 2008, Foody et al. 2003), artificial neural network models in this study outperformed regression analysis and resulted in much smaller model RMSEs. We thus conclude that the artificial neural network model can increase the accuracy of estimation prediction and is thus a good alternative to conventional regression models for estimating volume increment, particularly when nonlinear relationships are expected between the independent variables and the dependent variables.

The RBF-gamma SVM algorithm was superior to the linear, polynomial, and sigmoid alternatives for modeling net annual volume increment in this study. Although the model explained $92 \%$ of the variation in the evaluation dataset, the mean squared error was slightly greater than that of the ANN method. The nearly identical performances of SVM and ANN in this study are not unusual and have been noted when accuracies of classifications using SVM and ANN were compared (Dixon and Candade 2008). Comparing classification based on support vector machine with maximum likelihood classification, neural network, and decision tree, Huang et al. (2002) also noted that the accuracy of the support vector machine was superior to the other methods and considered the reason for this the finding an optimal decisionmaking boundary.

The net annual volume increment model based on the RF algorithm in this study that explained about $89 \%$ of the variation in the data placed the greatest importance on plot basal area, followed by precipitation and elevation. Consistent with ANN and SVM-based results, the inclusion of topographic data as auxiliary data was able to improve the model. Similar results were obtained for modeling volume and basal area in the Darabkola forest of Sari, Iran, when plot-based estimates were complemented with spectral data from the Pleiades satellite and topographic auxiliary data (Zahriban et al. 2015). Using the nonparametric RF algorithm that included both spectral and auxiliary data resulted in a 5\% reduction of RMSE compared with the use of spectral data only for volume modeling and a reduction between 1 and 3\% for basal area modeling (Zahriban et al. 2015). Despite this improvement of the model when incorporating topographic data, our results do contrast with those of Shataee et al. (2012), 


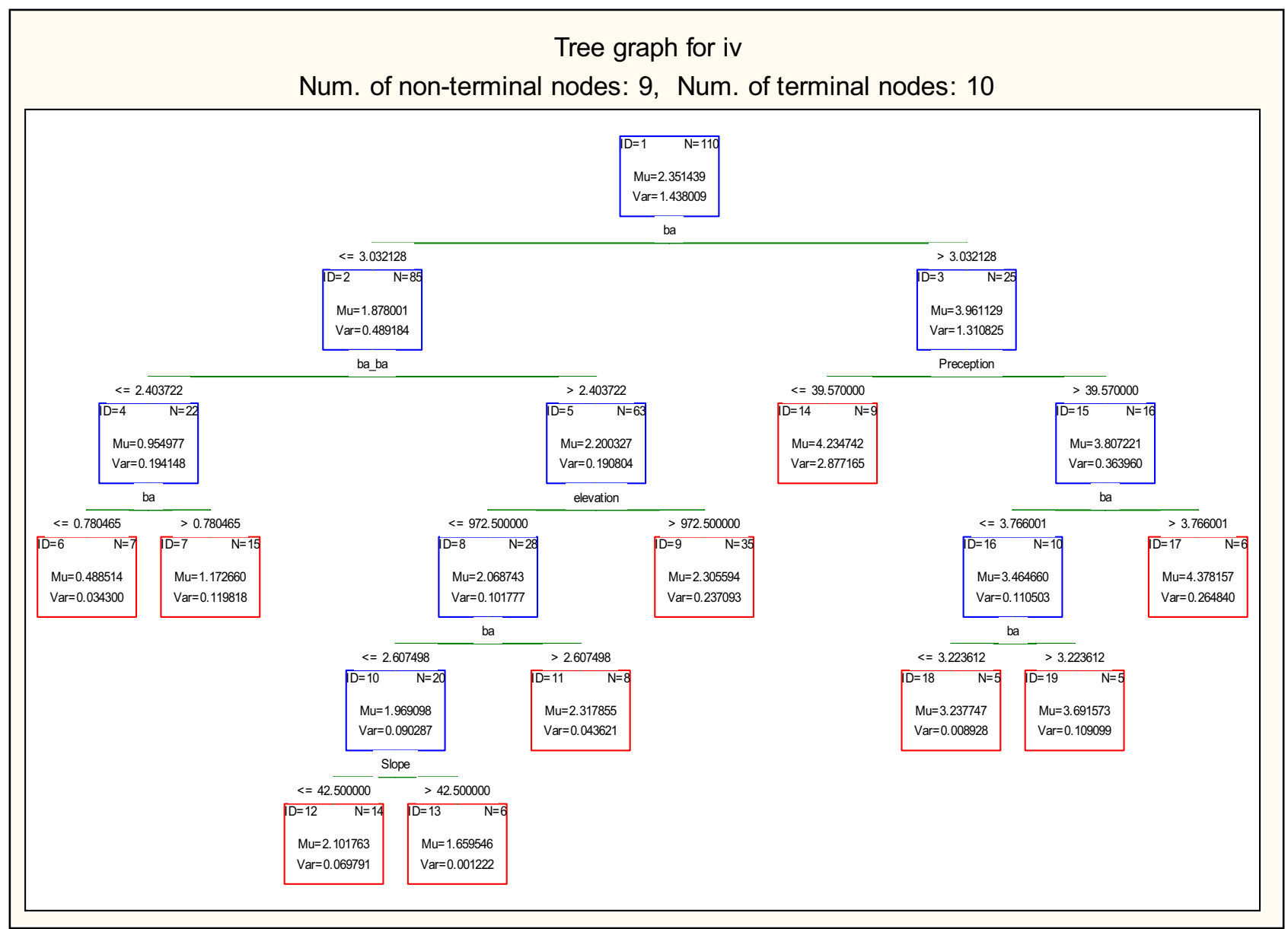

Fig. 9 The decision tree derived from random forest

who found that the random forest algorithm had a superior performance compared with other machine learning methods.

Modeling net annual volume increment using the nearest neighbor algorithm based on the Manhattan distance measure explained only $84 \%$ of the variation in the data with greater bias than ANN and SVM models. McRoberts (2012) estimated forest attribute parameters for small areas using nearest neighbor techniques and obtained a root mean squared error of 64.73 with 25 optimum $k$, which was a greater error rate than in the present study.

The much greater relative RMSE produced by the kNN method compared with SVM and RF methods in this study is in contrast to a study by Shattaee et al. (2012) who investigated stand volumes derived from ASTER sensor data using kNN, SVM, and RF methods and found
Fig. 10 Model residuals of net annual volume increment plotted against observed net annual volume increment $\left(\mathrm{m}^{3} \mathrm{ha}^{-1}\right.$ year $\left.^{-1}, \mathbf{a}\right)$ and basal area $\left(\mathrm{m}^{2} \mathrm{ha}^{-1}, \mathbf{b}\right)$ based on the random forest
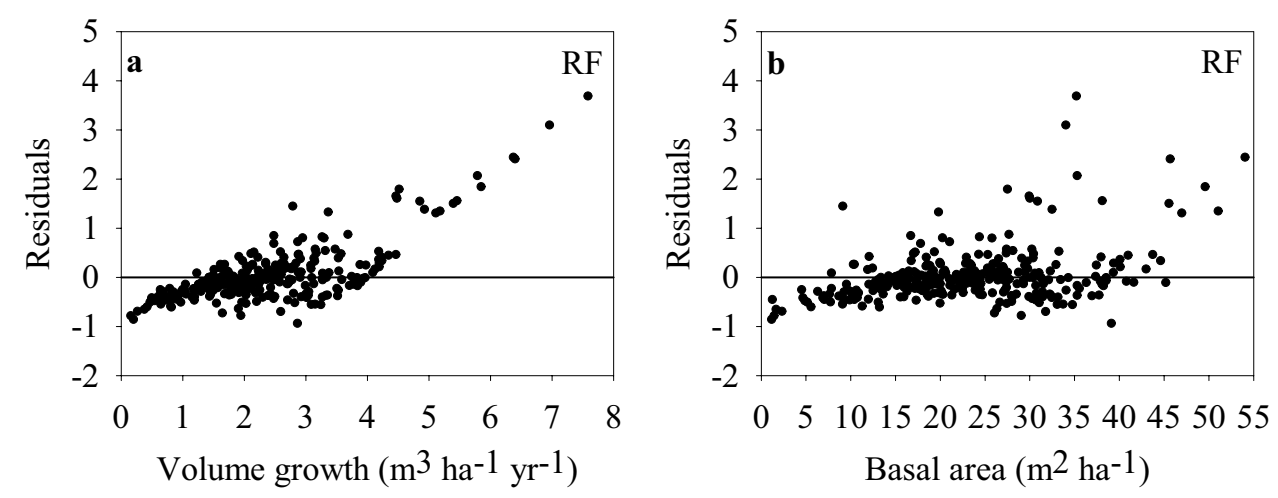
Table 5 Results and evaluation related to analysis of k-nearest neighbor

\begin{tabular}{|c|c|c|c|c|c|c|c|c|}
\hline \multirow[t]{2}{*}{ KNN } & \multicolumn{2}{|c|}{ Euclidean } & \multicolumn{2}{|c|}{ Euclidean squared } & \multicolumn{2}{|c|}{ Manhattan } & \multicolumn{2}{|c|}{ Chebychev } \\
\hline & Train & Evaluation & Train & Evaluation & Train & Evaluation & Train & Evaluation \\
\hline$K$ range & $1-20$ & $1-20$ & $1-20$ & $1-20$ & $1-20$ & $1-20$ & $1-20$ & $1-20$ \\
\hline$R^{2}$ & 0.71 & 0.73 & 0.71 & 0.73 & 0.73 & 0.75 & 0.71 & 0.72 \\
\hline RMSE & 0.95 & 0.81 & 0.95 & 0.81 & 0.84 & 0.78 & 0.95 & 0.82 \\
\hline BIAS & 0.06 & 0.14 & 0.06 & 0.14 & 0.03 & 0.04 & 0.05 & 0.13 \\
\hline$\%$ RMSE & 39.52 & 36.63 & 39.52 & 36.63 & 35.24 & 36.51 & 39.62 & 36.64 \\
\hline$\%$ BIAS & 0.27 & 6.31 & 0.27 & 6.31 & 0.25 & 2.22 & 0.26 & 6.12 \\
\hline Optimal K & 10 & 10 & 10 & 10 & 11 & 11 & 10 & 10 \\
\hline
\end{tabular}

a lower relative RMSE (28.4\%) for the kNN method that was similar to those of the SVM (25.9\%) and RF (26.9\%) methods. However, one of the problems associated with the $\mathrm{kNN}$ algorithm is that all features of the neighbors have a similar effect on the distance of a new record to its neighbors, which can mislead the classification process and reduce the accuracy of the algorithm (Thanh and Kappas 2018).

In this study, all methods consistently indicated a curvilinear relationship of net annual volume increment with basal area, with maximum volume increment occurring at the greatest basal areas. This is not surprising, because the magnitude of growth is largely a function of the size of the growing stock. Owing to the shade-tolerance of the attending species, even the net annual volume increment of trees $<24 \mathrm{~cm}$ DBH was not significantly negatively affected by high basal areas $(p>0.79)$ in this study. However, we did not evaluate, and thus, we cannot exclude, potentially adverse effects of high basal areas on the regeneration. It is important to remember that this analysis investigated net annual volume increment as a function of the range of basal areas within and not among stands. Because uneven-aged beech forests are not primarily managed for maximum volume increment rates but to also ensure sufficient regeneration and up-growth of trees through the diameter distribution to sustain the uneven-aged system, it is clear that average stand-level basal areas and volumes are kept much below those that maximize net annual volume increment over a single decade. The average stand-level basal area in this study that ranged between 23.1 and $25.1 \mathrm{~m}^{2} \mathrm{ha}^{-1}$ and average volumes that ranged between 227 and $250 \mathrm{~m}^{3} \mathrm{ha}^{-1}$ in 2003 and 2013 were lower than the recommended ranges of $26-26 \mathrm{~m}^{2} \mathrm{ha}^{-1}$ or $300-350 \mathrm{~m}^{3} \mathrm{ha}^{-1}$, respectively, that ensure both structure and sustainable volume increment in Oriental beech forests in Iran (Eslami 2017). An average observed net annual volume increment of $2.3 \mathrm{~m}^{3} \mathrm{ha}^{-1}$ year ${ }^{-1}$ plus a harvest level $5.7 \mathrm{~m}^{3} \mathrm{ha}^{-1}$ year $^{-1}$ and a mortality of $2 \mathrm{~m}^{3} \mathrm{ha}^{-1}$ year $^{-1}$ indicate that this uneven-aged forest may provide a sustainable yield of $6 \mathrm{~m}^{3} \mathrm{ha}^{-1}$ year ${ }^{-1}$ (i.e., net growth plus harvest minus mortality) when managed at current basal area and volume levels. Because the average basal area is quite a bit lower than the $36.8 \mathrm{~m}^{2} \mathrm{ha}^{-1}$, and the increment is much higher than the $4 \mathrm{~m}^{3} \mathrm{ha}^{-1}$ year ${ }^{-1}$ of sustainable yield reported for uneven-aged managed forests in the region (Bayat et al. 2013), there are two general management options for this forest. First, maintain current harvest levels and gradually build up volume stocks to the recommended $300-350 \mathrm{~m}^{3} \mathrm{ha}^{-1}$ or increase harvest levels to sustain current levels of volume stocks. To facilitate that decision, future research needs to relate regeneration dynamics to various levels of basal areas and volume stocks in this study region.
Fig. 11 Model residuals of net annual volume increment plotted against observed net annual volume increment $\left(\mathrm{m}^{3} \mathrm{ha}^{-1}\right.$ year $\left.^{-1}, \mathbf{a}\right)$ and basal area $\left(\mathrm{m}^{2} \mathrm{ha}^{-1}, \mathbf{b}\right)$ based on the nearest neighbor algorithm
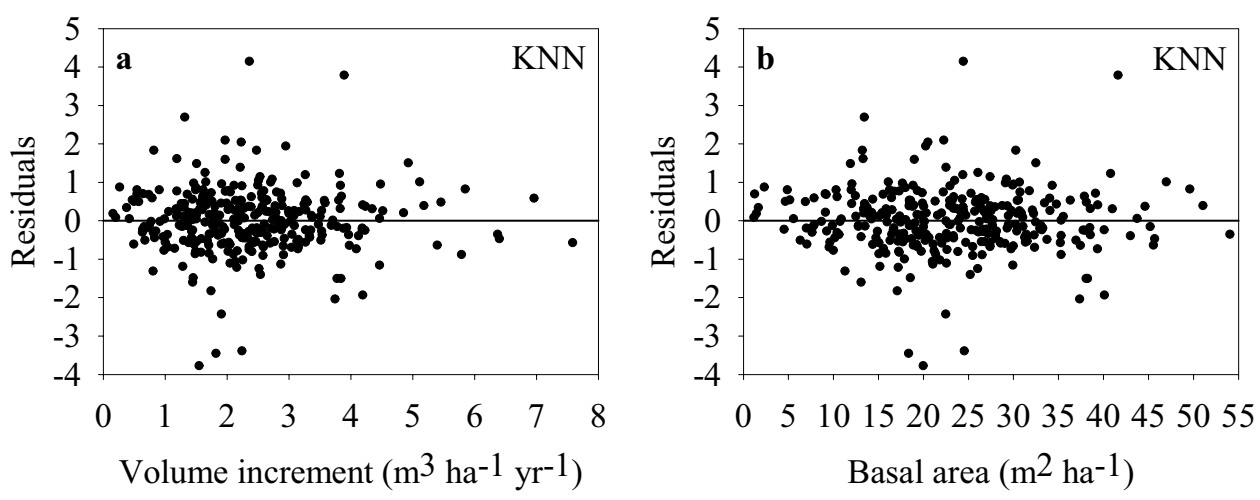


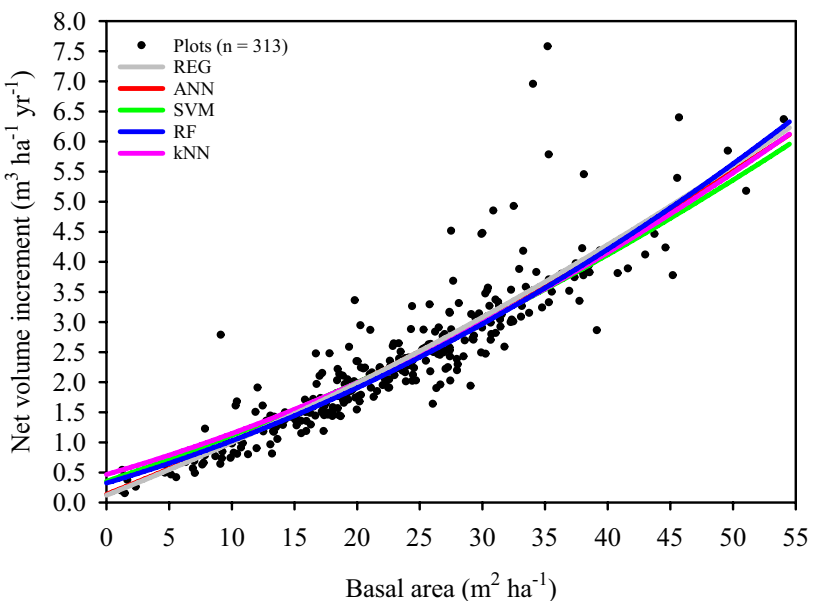

Fig. 12 Observed net annual volume increment $\left(\mathrm{m}^{3} \mathrm{ha}^{-1}\right.$ year $\left.{ }^{-1}\right)$ as function of basal area $\left(\mathrm{m}^{2} \mathrm{ha}^{-1}\right)$ and fitted curves that depict the relationship between these two variables using least squares regression (REG), artificial neural network (ANN), support vector machine $(\mathrm{SVM})$, random forest $(\mathrm{RF})$, and nearest neighbor algorithm $(\mathrm{kNN})$

Table 6 Comparison of fit statistics of the methods tested in this study

\begin{tabular}{lllc}
\hline Method & $R^{2}$ & RMSE & \%RMSE \\
\hline Statistical (regression) method & 0.81 & 0.52 & 22.0 \\
Artificial neural network & 0.92 & 0.19 & 8.6 \\
Support vector machine & 0.91 & 0.33 & 14.9 \\
Random forest & 0.89 & 0.52 & 22.2 \\
Nearest neighbor algorithm & 0.75 & 0.78 & 36.5 \\
\hline
\end{tabular}

\section{Conclusion}

With the advent of machine learning methods, the precision of solving complex problems in many fields has increased in recent years. These methods have proven to be more effective in activities that use mathematical models such as regression. Machine learning methods have been widely used to estimate forest inventory parameters. In this study, four machine learning algorithms as well as statistical analysis were used to model forest volume increment in a Hyrcanian uneven-aged mixed forest. Similar to results by some researchers who compared machine learning results to allometric models to predict forest characteristics, we found that some machine learning methods, especially artificial neural network and support vector machine were superior and more accurate than other machine learning methods as well as traditional least-squares regression. The ability to accurately predict wood volume provides the basis for the sustainable management of forests as well as a more accurate forecast of the allowable cut that can be extracted from forests. This is particularly important in uneven-aged forest management, where accurate forecasts of the net volume growth are needed to maintain the species composition and structures that characterize these forests. In this study, we have shown that some machine learning methods may provide a more detailed picture of the distribution of net volume growth than can be achieved with linear regression analysis.

Acknowledgments We acknowledge the anonymous editor and reviewers who provided many helpful comments and suggestions for improving this manuscript.

Data availability Data not available / Data will be made available on request.

\section{Compliance with ethical standards}

Conflict of interest The authors declare that they have no conflict of interest.

\section{References}

Ashraf MI, Bourque CP-A, MacLean DA, ErdleMeng TFR (2012) Using JABOWA-3 for forest growth and yield predictions under diverse forest conditions of Nova Scotia. Canada The Forestry Chronicle 88(6):708-721

Ashraf MI, Zhao Z, Bourque CPA, MacLean DA, Meng FR (2013) Integrating biophysical controls in forest growth and yield predictions with artificial intelligence technology. Can J For Res 43(12):1162-1171

Bayat M, Pukkala T, Namiranian M, Zobeiri M (2013) Productivity and optimal management of the uneven-aged hardwood forests of Hyrcania. Eur J Forest Res 132(5-6):851-864

Bayat M, Ghorbanpour M, Zare R, Jaafari A, Pham BT (2019a) Application of artificial neural networks for predicting tree survival and mortality in the Hyrcanian forest of Iran. Computers and Electronics in Agriculture, 164, Article 104929

Bayat M, Thanh Noi P, Zare RT, Bui D (2019) A Semi-empirical Approach Based on Genetic Programming for the Study of Biophysical Controls on Diameter-Growth of Fagus orientalis in Northern Iran. Remote Sens 11:1680

Bayat M, Bettinger P, Heidari S, Henareh Khalyani A, Jourgholami M, Hamidi SK (2020) Estimation of Tree Heights in an UnevenAged, Mixed Forest in Northern Iran Using Artificial Intelligence and Empirical Models. Forests 11:324

Benali L, Notton G, Fouilloy A, Voyant C, Dizene R (2019) Solar radiation forecasting using artificial neural network and random forest methods: Application to normal beam, horizontal diffuse and global components. Renewable Energy 132:871-884

Bourque CPA, Bayat M (2015) Landscape variation in tree species richness in northern Iran forests. PLoS ONE 10(4):e0121172

Bourque CPA, Bayat M, Zhang C (2019) An assessment of heightdiameter growth variation in an unmanaged Fagus orientalisdominated forest. European J For Res 1-15

Breidenbach J, Nothdurft A, Kandler G (2010) Comparison of nearest neighbor approaches for small area estimation of tree speciesspecific forest inventory attributes in central Europe using airborne laser scanner data. European Journal of Forest Resources 129(5):833-846

Breiman L (2001) Random forests. Machine Learning 45(1):5-32 
Castellanos A, Blanco AM, Palencia V (2007) Applications of Radial Basis Neural Networks for area forest. International Journal Information Theories and Applications 14:218-222

Civco DL, Wanug Y (1994) Classification of multispectral, multitemporal, multisource spatial data using artificial neural networks. Congress on Surveying and Mapping, USA, p 12

Da Rocha SJSS, Torres CMME, Jacovine LAG, Leite HG, Gelcer EM, Neves KM, Zanuncio JC (2018) Artificial neural networks: Modeling tree survival and mortality in the Atlantic Forest biome in Brazil. Sci Total Environ 645:655-661

Davis LS, Johnson KN, Bettinger PS, Howard TE (2001) Forest management to sustain ecological, economic and social values (4thed). N.Y, McGraw-Hill companies, p 804

Dietterich TG (2000) An experimental comparison of three methods for constructing ensembles of decision trees: Bagging, boosting, and randomization. Machine Learning 40:139-157

Dixon B, Candade N (2008) Multispectral land use classification using neural networks and support vector machines: one or the other, or both? Int J Remote Sens 29(4):1185-1206

Eskelson BNI, Barrett TM, Temesgen H (2009) Imputing mean annual change to estimate current forest attributes. Silva Fennica 43(4):649-658

Eslami A (2017) Determination the structure of oriental beech, Fagus orientalis Lipsky stands (Case study: Asalem watershed forests, north of Iran). Caspian Journal of Environmental Studies 15(1):57-66

Finely AO, McRobert RE, Ek AR (2006) Applying an efficient k-nearest neighbor search to forest attribute imputation. Forest Science 52:130-135

Foody GM, Boyd DS, Cutler MEJ (2003) Predictive relations of tropical forest biomass from Landsat TM data and their transferability between regions. Remote Sens Environ 85:463-474

Gardingen PRV, Valle D, Thompson I (2006) Evaluation of yield regulation options for primary forest in Tapajo's National Forest, Brazil. For Ecol Manage 231:184-195

Gu H, Dai L, Wu G, Xu D, Wang S, Wang H (2006) Estimation of forest volumes by integration Landsat TM imagery and forest inventory data. Science in China series E. Technological Science 49:54-62

Hamidi K, Fallah A, Bayat M, Hosseini Yekani SA (2019) Individual Tree Growth Models for Management of Uneven aged and Mixed Hyrcanian Forests (Case Study: Farim Forest). Iranian Journal of Forest 3(11):373-386

Hamidi K, Fallah A, Bayat M, Hosseini Yekani SA (2016) Determining the Forest Volume Growth using Permanent Sample Plots (Case Study: Farim Forest, Jojadeh District). Ecology of Iranian Forests $4(8): 1-8$

Heshmatol Vaezin SM, Attarod P, Bayramzadeh V (2008) Tree volume increment models of broadleaf species in the uneven-aged mixed Caspian forest. Asian J Plant Sci 7:700-709

Hilbert DW, Ostendorf B (2001) The utility of artificial neural networks for modeling the distribution of vegetation in past, present and future climates. Ecological Modeling 146(1):311-327

Holmstrom H, Fransson JES (2003) Combining remotely sensed optical and radar data in K-NN estimation of forest variables. For Ecol Manage 49(3):409-418

Hung X, Hu X, Jiang W, Yang Zh, Li H, (2014) Application of Multilayer Feed forward Neural Networks in Predicting Tree Height and Forest Stock Volume of Chinese Fir, p 4

Huang CLS, Davis JR, Townshend G (2002) An assessment of support vector machines for land cover classification. Int J Remote Sens 23(4):725-749

Hsu CW, Chang CC, Lin CJ (2010) A practical guide to support vector classification, Department of Computer Science, National Taiwan University, Taipei. http://www.csie.ntu.edu.tw/ cjlin
Ingram JC, Dawso TP, Whittaker RJ (2005) Mapping tropical forest structure in southeastern Madagascar using remote sensing and artificial neural networks. Remote Sensing Environ 94(4):491-507

Jahani A, Feghhi J, Makhdoum MF, Omid M (2016) Optimized forest degradation model (OFDM): an environmental decision support system for environmental impact assessment using an artificial neural network. J Environ Planning Manage 59(2):222-244

Janizadeh S, Avand M, Jaafari A, Phong TV, Bayat M, Ahmadisharaf E, Prakash I, Pham BT, Lee S (2019) Prediction Success of Machine Learning Methods for Flash Flood Susceptibility Mapping in the Tafresh Watershed. Iran Sustainability 11(19):5426

Kutzer C (2008) Potential of the K-NN method for estimation and monitoring off-reserve forest resources in Ghana. Ph.D. Thesis, Department of Forestry and Environmental Sciences, AlbertLudwigs University, Freiburg, Germany, p 145

Leak WB (2011) Estimating allowable-cut by area-scheduling. Research Note, Northern Research Station-115. Newtown Square, PA: U.S. Department of Agriculture, Forest Service, p 4

Lee J, Im J, Kim KM, Quackenbush LJ (2018) Machine learning approaches for estimating forest stand height using plot-based observations and airborne LiDAR. Data For 9:268

Lhotka JM, Loewenstein EF (2011) An individual-tree diameter growth model for managed uneven-aged oak-shortleaf pine stands in the Ozark Highlands of Missouri, USA. For Ecol Manage 261:770-778

Lumbres IRC, Abino CA, Pampolina MN, Calora GF Jr, Lee YJ (2016) Comparison of stem taper models for the four tropical tree species in Mount Makiling. Philippines, Journal of Mountain Science 13:536-545

Maier HR, Dandy GC (2000) Neural networks for the prediction and forecasting of water resources variables: a review of modelling issues and applications. Environmental Modelling \& Software 15(1):101-124

Maier HR, Jain RA, Dandy GC, Sudheer KP (2010) Methods used for the development of neural networks for the prediction of water resource variables in river systems: current status and future directions. Environ Modeling \& Software 25(8):891-909

Mattera D, Haykin S (1999) Support vector machines for dynamic reconstruction of a chaotic system, In: Schölkopf B, Burges EY, Smola AJ (eds) Advances in Kernel Methods: Support Vector Learning. MIT Press, Cambridge, MA, pp 211-242

McRoberts R (2012) Estimating forest attribute parameters for small areas using nearest neighbor techniques. For Ecol Manage 272:3-12

Miller TF, Mladenoff DJ, Clayton MK (2005) Old growth northern hardwood forests: Spatial autocorrelation and patterns of understory vegetation. Ecol Monogr 72(4):478-503

Mountrakis G, Im J, Ogole C (2011) Support Vector Machines in Remote Sensing: A Review. ISPRS Journal of Photogrammetry and Remote Sensing 66:247-259

Nagy HM, Watanabe K, Hirano M (2002) Prediction of sediment load concentration in rivers using artificial neural network model. Journal of Hydraulic Engineering 128:588-595

Nandy S, Singh R, Ghosh S, Watham T, Kushwaha SPS, Kumar AS, Dadhwal VK (2017) Neural network-based modelling for forest biomass assessment. Carbon Management 8(4):305-317

Ozçelik R, Diamantopoulou JM, Brooks JR, Wiant HV (2010) Estimating tree bole volume using artificial neural network models for four species in Turkey. J Environ Manage 91:742-753

Pulido-Calvo I, Montesi Nos P, Roldan J, Ruiz-Navarro F (2007) Linear regressions and neural approaches to water demand forecasting in irrigation districts with telemetry systems. Biosys Eng 97(2):283-293

Reese H, Nilsson M, Sandstorm P, Olsson H (2002) Applications using estimates of forest parameters derived from satellite and 
forest inventory data. Computers and Electronics in Agriculture 37(1):37-55

Reis LP, de Souza AL, dos Reis PCM, Mazzei L, Soares CPB, Torres CMME, Leite HG (2018) Estimation of mortality and survival of individual trees after harvesting wood using artificial neural networks in the amazon rain forest. Ecol Eng 112:140-147

Reis LP, de Souza AL, Mazzei L, dos Reis PCM, Leite HG, Soares CPB, Ruschel AR (2016) Prognosis on the diameter of individual trees on the eastern region of the amazon using artificial neural networks. For Ecol Manage 382:161-167

Sagheb Talebi KH, Sajedi T, Pourhashemi M (2014) Forest of Iran. Springer, Netherlands, p 152

Sanquetta CR, Wojciechowski J, Dalla Corte AP, Behling A, Péllico Netto S, Rodrigues AL, Sanquetta MNI (2015) Comparison of data mining and allometric model in estimation of tree biomass. BMC Bioinformatics 16:247. https://doi.org/10.1186/s12859015-0662-5

Scholkopf B, Smola AJ (2000) Statistical learning and kernel methods. MIT Press, Cambridge, MA, p p29

Schroder J, Soalleiro RR, Alonso GV (2002) An age-independent basal area increment model for maritime pine trees in northwestern Spain. Forest Ecology Management 157:55-64

Shataee S, Kalbi S, Fallah A, Pelz D (2012) Forest attribute imputation using machine-learning methods and ASTER data: comparison of k-NN, SVR and random forest regression algorithms. Int J Remote Sens 33(19):6254-6280

Sinha A, Rämö J, Malo P, Kallio M, Tahvonen O (2017) Optimal management of naturally regenerating uneven-aged forests. Eur J Oper Res 256:886-900

Sterba H (2002) Forest inventories and growth models to examine management strategies for forest in transition. J For Res 75(4):411-418

Strobl RO, Forte F (2007) Artificial neural network exploration of the influential factors in drainage network derivation. Hydrol Process 21:2965-2978

Sun HG, Zhang JG, Duan AG, He CY (2007) A review of stand basal area growth models. Forestry studies in China 9:85-94

Thakur TK, Swamy SL, Bijalwan A et al (2019) Assessment of biomass and net primary productivity of a dry tropical forest using geospatial technology. Journal of forestry research 30(1):157-170

Thanh P, Kappas M (2018) Comparison of Random Forest, k-Nearest Neighbor, and Support Vector Machine Classifiers for Land Cover Classification Using Sentinel-2 Imagery. Sensors (Basel) 18(1):18

Toth T, Schaap MG, Molnar Z (2008) Utilization of soil-plant interrelations through the use of multiple regression and artificial neural network in order to predict soil properties in Hungarian solonetzic grasslands. Cereal Research Communications $36: 1447-1450$

Vafaei S, Soosani J, Adeli K, Fadaei H, Naghavi H, Pham T, Bui D (2018) Improving Accuracy Estimation of Forest Aboveground Biomass Based on Incorporation of ALOS-2 PALSAR-2 and Sentinel-2A Imagery and Machine Learning: A Case Study of the Hyrcanian Forest Area (Iran). Remote Sens 10(172):1-21

Vahedi AA (2017) Monitoring soil carbon pool in the Hyrcanian coastal plain forest of Iran: Artificial neural network application in comparison with developing traditional models. CATENA 152:182-189
Vali A, Ramesht MH, Seif A, Ghazavi R (2012) An assessment of the artificial neural networks technique to geomorphologic modeling sediment yield case study Samandegan river system. Geography and Environmental Planning Journal 44(4):5-9

Vanclay JK (1994) Modeling forest growth and yield: application to mixed tropical forests. CAB International, United Kingdom, p 330

Van Dao D, Jaafari A, Bayat M, Mafi-Gholami D, Qi C, Moayedi H, Van Phong T, Ly HB, Le TT, Trinh PT, Luu C (2020) A spatially explicit deep learning neural network model for the prediction of landslide susceptibility. CATENA 188:104451

Vapnik V (1963) Pattern recognition using generalized portrait method. Autom and Remote Control 24:774-780

Vapnik V, Chervonenkis YA (1964) A class of algorithms for pattern recognition learning. Avtomat i Telemekh 25(6):937-945

Vieira GC, de Mendonça AR, da Silva GF, Zanetti SS, da Silva MM, dos Santos AR (2018) Prognoses of diameter and height of trees of eucalyptus using artificial intelligence. Sci Total Environ 619:1473-1481

Walling DE, Collins AL, Sichingabula HA, Leeks GJL (2001) Integrated Assessment of Catchment Suspended Sediment Budgets: A Zambian Example. Land Degrad Dev 12:387-415

Walton JT (2008) Sub pixel urban land cover estimation: comparing cubist, random forests, and support vector regression. Photogrammetric Engineering \& Remote Sensing 74(10):1213-1222

Wang X, Hao Z, Zhang J, Lian J, Li B, Ye J, Yao X (2009) Tree size distributions in an old-growth temperate forest. Oikos

Watts JD, Lawrence RL, (2008) Merging Random Forest classification with an object-oriented approach for analysis of agricultural lands. The International Archives of the Photogrammetry, Remote Sensing and Spatial Information Sciences, vol. XXXVII. Part B7. Beijing, pp 579-582

Weiskittel A, Hann DW, Kershaw JA, Vanclay JK (2011). Forest growth and yield modeling. Wiley Editing Service, p 430. https://doi.org/10.1002/9781119998518

Yijun L, Jiali T, Hongfen J, Guangping Z, Zhimin Y (2010) Artificial neural networks applied in environmental quality assessment. Abstracts of the Third IEEE International Computer Science and Information Technology Symposium. Spain, pp 19-22

Yu X, Hyyppä J, Holopainen M, Vastaranta M (2010) Comparison of area-Based and individual tree-based methods for predicting plotlevel forest attributes. Remote Sensing 2:1481-1495

Zahriban M, Fallah A, Shataee SH, Kalbi S (2015) Estimating quantitative forest attributes using Pleiades satellite data and non-parametric algorithms in Darabkola forests, Mazandaran, Iranian. J For Poplar Res 23(2):465-477

Zhu AX, Miao Y, Wang R, Zhu T, Deng Y, Liu J, Hong H (2018) A comparative study of an expert knowledge-based model and two data-driven models for landslide susceptibility mapping. Catena 166:317-327

Zhu XX, Zhou LY (2007) Suspended sediment flux modeling with artificial neural network: An example of the Longchuanjiang River in the Upper Yangtze Catchment, China. Geomorphology $84: 111-125$

Publisher's Note Springer Nature remains neutral with regard to jurisdictional claims in published maps and institutional affiliations. 